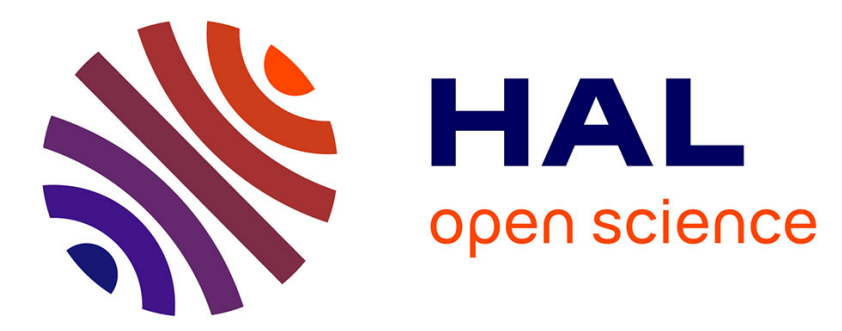

\title{
Secondary recrystallization of oxide dispersion strengthened ferritic alloys
}

H. Regle, A. Alamo

\section{To cite this version:}

H. Regle, A. Alamo. Secondary recrystallization of oxide dispersion strengthened ferritic alloys. Journal de Physique IV Proceedings, 1993, 03 (C7), pp.C7-727-C7-730. 10.1051/jp4:19937114 . jpa00251732

\section{HAL Id: jpa-00251732 https://hal.science/jpa-00251732}

Submitted on 1 Jan 1993

HAL is a multi-disciplinary open access archive for the deposit and dissemination of scientific research documents, whether they are published or not. The documents may come from teaching and research institutions in France or abroad, or from public or private research centers.
L'archive ouverte pluridisciplinaire HAL, est destinée au dépôt et à la diffusion de documents scientifiques de niveau recherche, publiés ou non, émanant des établissements d'enseignement et de recherche français ou étrangers, des laboratoires publics ou privés. 


\title{
Secondary recrystallization of oxide dispersion strengthened ferritic alloys
}

\author{
H. REGLE and A. ALAMO \\ CEA, Centre d'Etudes de Saclay, DTM/SRMA/SMPX, 91191 Gif sur Yvette, France
}

\begin{abstract}
The recrystallisation behaviour of two Oxide Dipersion. Strengthened ferritic alloys is investigated in the range of temperature from 750 to $1470^{\circ} \mathrm{C}$. Recrystallisation temperature and grain morphology are discussed in relation to the cold-process used and their cold-work level. Different recrystallised morphologies of grains are observed at different temperatures, which seem to be related to the occurrence of different recrystallisation mechanisms.
\end{abstract}

\section{INTRODUCTION}

The two ferritic oxide dispersion strengthened alloys MA957 and MA956 discussed in this paper are obtained by Mechanical Alloying techniques. This process enables the uniform distribution of nanometric oxide particles in a ferritic matrix. The main consequences of the oxide distribution are the enhancement of the mechanical strength compared to conventional ferritic alloys and a high stability of their microstructure, specially at high temperatures. Mechanical properties are directly related to microstructural features like morphology, grain size and grain aspect ratio. But, these parameters are very difficult to control in these kind of alloys. So, the recrystallisation behaviour has been investigated in relation to the stages of processing and the texture induced by deformation of those materials.

\section{MATERIALS AND EXPERIMENTAL}

Compositions of both alloys are given in table 1. Materials are supplied by Inco Alloy in the extruded condition. They present an extremely fine microstructure with elongated grains (diameter $0.4 \mu \mathrm{m}$ ) and a very strong $<110\rangle$ deformation texture with a main single-crystal component. This one can be described by two groups of crystals having a twin relation (1). Both materials contain a homogeneous dispersion of small particles, whereas the diameter varies from 10 to $200 \mathrm{~nm}$. These particles were identified by electron diffraction and STEM analysis as $\mathrm{Ti}(\mathrm{C}, \mathrm{N})$ (diameter 100-200nm) and complex composites of Y,Ti,Al for MA957 alloy and Y,Al for MA956 alloy (diameter $10-100 \mathrm{~nm}$ ). Optical microphaphs reveals also the presence of stringers of coarser particles in the longitudinal direction of the samples, which have probably be aligned during the extrusion process.

Additional hot extrusion was performed and bars were deformed by cold-drawing and swaging for six levels of cold-worked up to $60 \%$ area section reduction. At this stage of processing, all the samples present a fine and elongated grain microstructure, like the extruded bars. The recrystallisation heat treatments are performed under Argon, for one hour in a range of temperature from 750 to $1470^{\circ} \mathrm{C}$.

\begin{tabular}{|l|l|l|l|l|l|l|}
\hline elt Wt\% & Fe & Cr & Ti & Al & Y & Mo \\
\hline MA957 & bal & 12.6 & 0.9 & 0.05 & 0.18 & 0.29 \\
\hline MA956 & bal & 18.9 & 0.3 & 4.3 & 0.33 & - \\
\hline
\end{tabular}

\section{RESULTS}

table 1: Compositions of MA956 and MA957 alloys

Figure 1 represents the recrystallisation temperature determined by the complete disparition of the small primary grains observed by optical microscopy, against the cold-work level. For the same cold-working process and the same level of deformation, recrystallisation temperatures obtained are lower for MA956 alloy than for MA957 alloy, but for both materials, recrystallisation temperature depends much more on the cold-working process used than on the level of cold-work reached. 


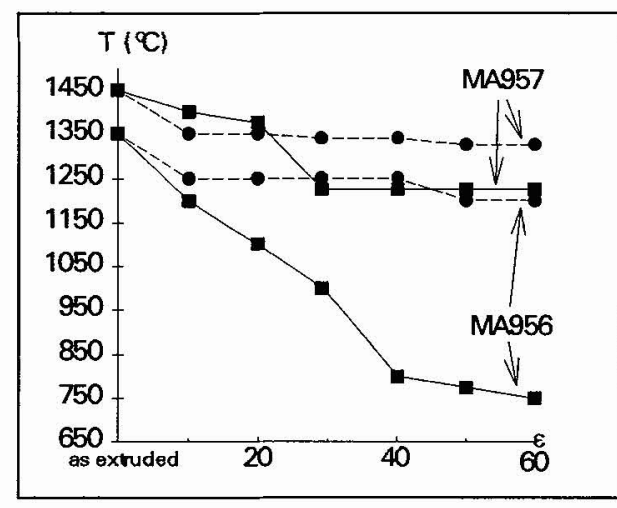

$\ldots+\frac{\text { Swaging }}{\text { Cold-drawing }}$

Figure 1 : Recrystallisation temperature as a function of cold-work level and processes

Heat treatments above this temperature induce in MA957 alloy, the occurrence of nearly isotropic microstructure, caracterized by smaller grains of about ten microns (figure 4.b). After one hour annealing at $1350^{\circ} \mathrm{C}$, the recrystallised microstructure can be described as alterned circular layers of coarse millimetric grains with those nearly isotropic small grains (figure $4 . a$ ).

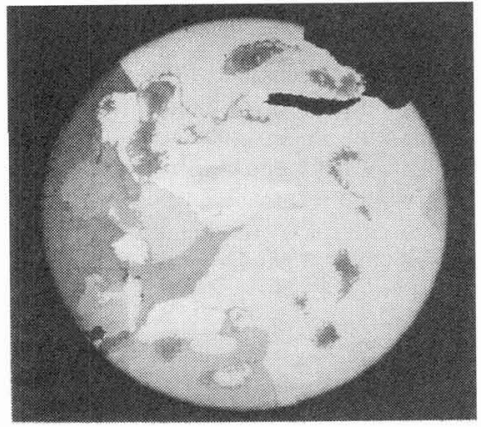

$1 \mathrm{~mm}$

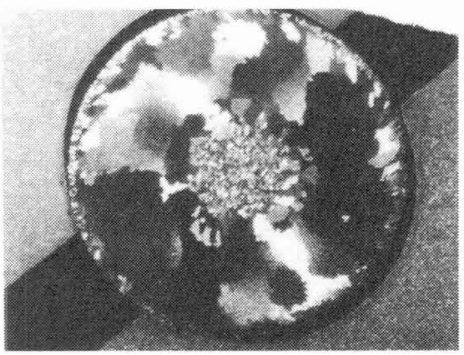

Figure 2 : Coarse grain recrystallised microstructure Figure 3 : Tranverse section of MA956 swaged of MA957 swaged sample recrystallised at $1325^{\circ} \mathrm{C}$ sample recrystallised at $1200^{\circ} \mathrm{C}$

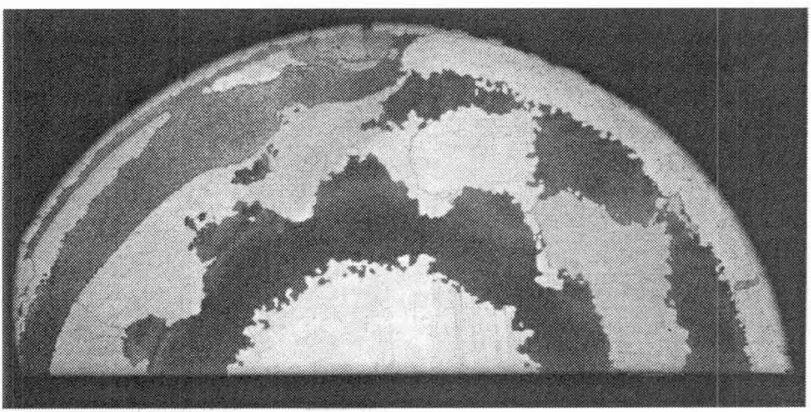

$1 \mathrm{~mm}$

(a)

Figure 4 : (a) Tranverse section of MA957 swaged sample recrystallised at $1350^{\circ} \mathrm{C}$,

(b) nearly isotropic small grains devellopped by those samples

(b) $1350^{\circ} \mathrm{C}$

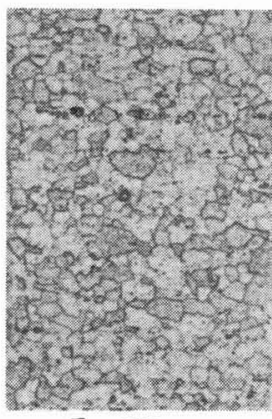

$500 \mu^{m}$ 
The amount of small grains regions increases with the cold-work level and with the temperature of the heat treatment. Sample swaged up to $60 \%$ area section reduction, for instance, recrystallises completely into small isotropic grains after heat treatment at $1450^{\circ} \mathrm{C}$. Figure 5 represents the evolution of the fraction of the two recrystallised morphologies observed for this sample after isochronal annealings in a range of temperatures from 1200 to $1470^{\circ} \mathrm{C}$.

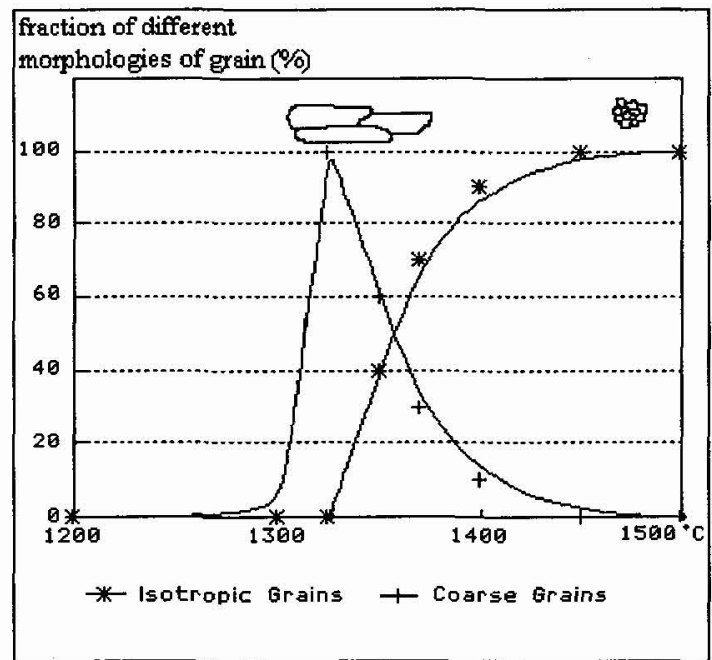

Figure $5:$ Amount of each type of recrystallised morphology for the MA957 alloy previously swaged to $60 \%$ as a function of the annealing temperature
Cold-drawn specimens exhibit a nearly homogeneous recrystallised microstructure, but a slight radial gradient of grain sizes corresponding to a gradient of residual stresses has been found. In order to correlate the true deformation with the recrystallised microstructure, the cold-drawing process is simulated by a tensile test. Tests are stopped just before the rupture and samples are annealed for one hour at different temperatures. Grain sizes and recrystallised fractions can then be related to the true deformation calculated along the sample axis (1). This experiment allows us to find the minimum threshold deformation that can induce total recrystallisation with an uniform grain size for a given temperature. Figure 6 illustrates this simulation on a MA957 extruded sample deformed by tensile test and annealed one hour at $1200^{\circ} \mathrm{C}$. Typical elongated grains are formed in the high deformed regions (necking regions). Figure 7 represents the recrystallised grain fraction, plotted against the true deformation of the sample for different temperatures of annealing.

Heat treatment at $1470^{\circ} \mathrm{C}$, for instance, induces in these samples a complete recrystallisation for all the induced deformations.

A gradient of grain sizes can be observed along the sample axis.

Figure 6: MA957 alloy

deformed by tensile test and annealed at $1200^{\circ} \mathrm{C}$

$1 \min$

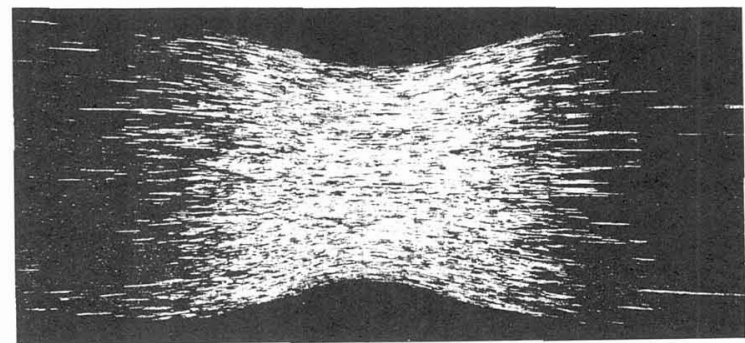

Figure 7 : Fraction of recrystallised grains as a function of the true deformation obtained by tensile test for different annealing temperature

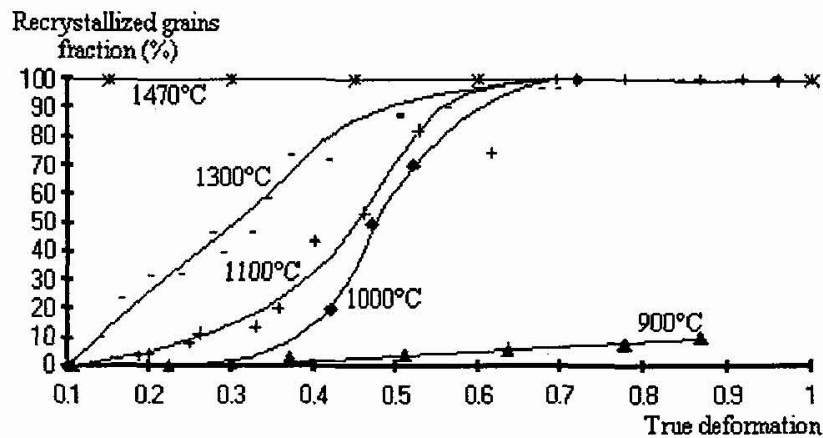




\section{DISCUSSION}

Recrystallisation behaviour has been here investigated for two materials deformed by two cold-working processes. The difference between these two axisymetric deformation processes is the type of induced strain, which is mainly a radial deformation for swaging and an axial deformation for cold-drawing process. We can assume, considering figure 4, that residual stress distributions induced in the bars during such processes have an effect uppon the different activated recrystallisation mechanisms. Such investigations are now in progress. Nevertheless, textures certainly play an important role in the recrystallisation phenomena. Precedent papers have described the effect of hot and cold-work processes on texture (2). Indeed, cold-work process used, influences the type and the degree of texture. Samples deformed by swaging tend to enhance the sharpness (texture index) of the main single-crystal component of texture, although they retain a fibre component. On the contrary, pole figures of samples deformed by cold-drawing present a widening of intensities around the prefered $\langle 110\rangle$ direction and no more single-crystal component. These characteristics are more pronounced when the cold-work level increases. The recrystallisation texture however, according to the first determination that we have performed, presents no $<110>$ component.

Experimental results seem to show that, specially for the MA957 alloy, several recrystallisation mechanisms, dependant on the temperature of the heat treatments, are activated.

At temperature below $1350^{\circ} \mathrm{C}$, the recrystallisation into coarse grain structure, like extruded bars, low coldworked specimens and MA957 swaged samples may be explained by a relation between the mobility of the grain boundaries and the type and sharpness of the texture. Indeed, the $\langle 110\rangle$ texture of these samples is very high and presents a single-crystal component. The misorientation between two adjacent crystals is very small or they are in a twin relation, like the extruded bars. Then, most of the grain boundaries will be low angle boundaries or special boundaries and these type of grain boundaries are very narrow as defined in (3). Consequently, the diffusivity of atoms from the lattice of one shrinking grain into the lattice of one adjacent growing grain will be difficult. On the other hand, the grains with orientations which differ from the general orientation will be able to grow easier and faster, if they are in the conditions required by the secondary recrystallisation in presence of small particles, according to the model of Gladman (4). Such grains are very scarce in high textured materials and that may explain why only a few grains grow very fast, exhibiting an abnormal growth, until they encounter each other, resulting in a coarse grain microstructure.

At temperatures above $1350^{\circ} \mathrm{C}$ however, in the case of extruded and swaged samples, an other mechanism seems to be activated. A lot of grains seem to have the opportunity to grow since the recrystallised grains are now much smaller. At temperature higher than $1350^{\circ} \mathrm{C}$, the recovery process is certainly very fast. Then, the grain boundary energy will probably decrease and the migration will be slower than the migration for abnormal grain growth, allowing a lot of grain boundaries to migrate independently of their orientation. The degree of recovery, during annealing, as suggested by figure 4 , will probably be correlated to the initial distribution of residual stresses and so, will be different in different regions of the sample.In the more recovered regions of this sample a sort of normal grain growth will take place, whereas secondary grains appear in the other regions.

Cold-drawn samples, on the contrary, recrystallise in a nearly homogeneous microstructure of secondary grains. That may be explained by the initial wide misorientations, that allows more grains to grow fast at the same time, if they are potential nuclei for secondary recrystallisation. This microstructure is stable even at higher temperature, since no isotropic small grain morphology occurs. Nevertheless, the differences of behaviours between the swaged and the cold-drawn samples specially at high temperature are not yet well-understood.

\section{CONCLUSIONS}

Recrystallisation temperature and morphology depend much more on the cold-work process used than on the cold-worked level reached.

Cold-drawing process enables recystallisation into a homogeneous microstructure at temperatures below $1300^{\circ} \mathrm{C}$. The higher amount of nucleation sites for secondary recrystallisation in the cold-drawn samples than in the swaged specimens can be related to the type of the deformation texture.

At temperatures higher than $1350^{\circ} \mathrm{C}$ and specially for the MA957 alloy, several recrystallisation mechanisms are activated for extruded and swaged materials. For these samples, the grain growth anisotropy is reduced when temperature increases.

\section{REFERENCES}

(1). Y. ADDA, J.M. DUPOUY, J. PHILIBERT, Y. QUERE, Elements de Metallurgie Physique, vol5, 1979, p. 1313

(2). A. ALAMO, H. REGLE, J.L. BECHADE, Advances in Powder Metallurgy \& Particulate Materials, Novel Powder Processing, Vol 7, 1992, p. 169

(3). J.C.M. LI, Recovery and Recrystallisation of Metals, ed. Himmel, 1963, p. 160

(4). T. GLADMAN, Proc. Royal Society, 294A, 1966, p. 298 